14.1

\title{
Влияние температуры на метаболизм и продолжительность жизни некоторых видов гомойотермных животных*
}

\author{
(ㄱ А.И. Петров, М.В. Разуваева
}

Физико-технический институт им. А.Ф. Иофрфе РАН, 194021 Санкт-Петербург, Россия

e-mail: An.Petrov@mail.ioffe.ru, M.Razuvaeva@mail.ioffe.ru

(Поступило в Редакцию 8 января 2018 г.)

\begin{abstract}
Проведен анализ влияния различных параметров на метаболизм теплокровных животных: млекопитающих, воробьиных птиц и человека. Для величины основного обмена получено уравнение больцмановского типа с энергией активации, величина которой совпадает с энергией ферментативного распада макроэргических P-О-связей в молекулах аденозинтрифосфорной кислоты. Получена зависимость, связывающая продолжительность жизни млекопитающих и птиц с температурой и массой тела, величиной основного обмена и константой Рубнера.
\end{abstract}

DOI: 10.21883/JTF.2018.10.46485.3-18

Продолжительность жизни в мире теплокровных животных колеблется в пределах от 2-х лет для мыши до 80-100 лет у человека. Большинство гипотез, объясняющих причину неодинаковой продолжительности жизни $(\tau)$, обычно связывают с тем или иным признаком, которым одно животное отличается от другого. Так, еще Аристотель обратил внимание на связь $\tau$ с продолжительностью беременности; Бюффон - c длительностью периода роста; Мечников связывал $\tau$ с длиной толстого кишечника, так как он считал причиной старения отравление организма продуктами жизнедеятельности гнилостных микробов, населяющих кишечник. Продолжительность жизни связывают также с фактором цефализации. Известно так называемая формула Фриденталя: - „умные живут долее всего“. Аршавский связывает $\tau$ у разных видов млекопитающих с особенностями развития у них скелетной мускулатуры. Продолжительность жизни зависит также от массы животного и метаболической активности. Согласно Рубнеру, природа наделила млекопитающим одинаковую энергию на единицу веса, среднее значение которой за время жизни составляет $\mathrm{Ru}=2 \cdot 10^{5} \mathrm{kkal} / \mathrm{kg}$. Животные малых размеров расходуют свой энергетический фонд намного быстрее, чем животные с большей массой, так как у них на единицу массы приходится большая поверхность тела. Человек за время жизни по сравнению с млекопитающими потребляет энергии в 3.5 раза больше $7.25 \cdot 10^{5} \mathrm{kkal} / \mathrm{kg}$, воробьиные птицы $9.6 \cdot 10^{5} \mathrm{kkal} / \mathrm{kg}$ [1]. Причиной старения Рубнер считал медленное снижение во времени обменных процессов.

Таким образом, из приведенных данных видно, что существует множество подходов к проблеме старения живых организмов. К настоящему времени насчитывается около 300 гипотез старения [2]. Все теории старения можно условно разделить на две большие группы: эволюционные теории и теории, основанные на

\footnotetext{
* Вторая российская конференция с международным участием „Физика - наукам о жизни“ (Санкт-Петербург, 18-22 сентября 2017 г.)
}

случайных повреждениях клеток. Первые считают, что старение организмов является запрограммированным процессом, так как организм имеет программу разрушения и смерти, чтобы освободить место для последующих поколений. Теории повреждения полагают, что старение является результатом процесса накопления со временем различных повреждений. Этот подход в биологии старения сейчас считается установленным. Так, установлено накопление ошибок в ДНК в результате мутаций, радиации, стрессов, вирусов и т.д. В гипотезе сшивок предполагается, что затвердение стенок сосудов и развитие атеросклероза вызываются отложением на стенках артерии жиров и белков, соединенных сшивками. Показано, что с возрастом уменьшается число специализированных клеток (мышечных, нервных, печеночных и др.), сокращается количество митохондрий и рибосом. В молекулах ДНК, вследствие воздействия свободных радикалов и ионизирующего излучения, накапливаются разрывы одной или обеих ее нитей, также возникают ошибки в процессе транскрипции ДНК. Наконец, в процессе клеточного деления происходит укорочение теломеров, что ведет к потере ряда генов [2].

С точки зрения динамики считается, что старение является нелинейным, нарастающим во времени биологическим процессом, достигающим максимума к концу жизни.

В заключение этого краткого обзора отметим, что из всех теорий старения только некоторые из них, а именно энергетическая теория Рубнера, теория укорочения длины теломер и теория ограниченного количества деления клеток (достижение предела Хейфлика) являются количественными и могут быть использованы, например, для прогнозирования времени жизни живых организмов.

В настоящей работе будет рассмотрена теория Рубнера и влияние различных параметров на метаболизм и продолжительность жизни организмов. Такими параметрами в метаболической теории являются масса организма $(m)$ и величина основного обмена $(Q)$ (теплопродук- 


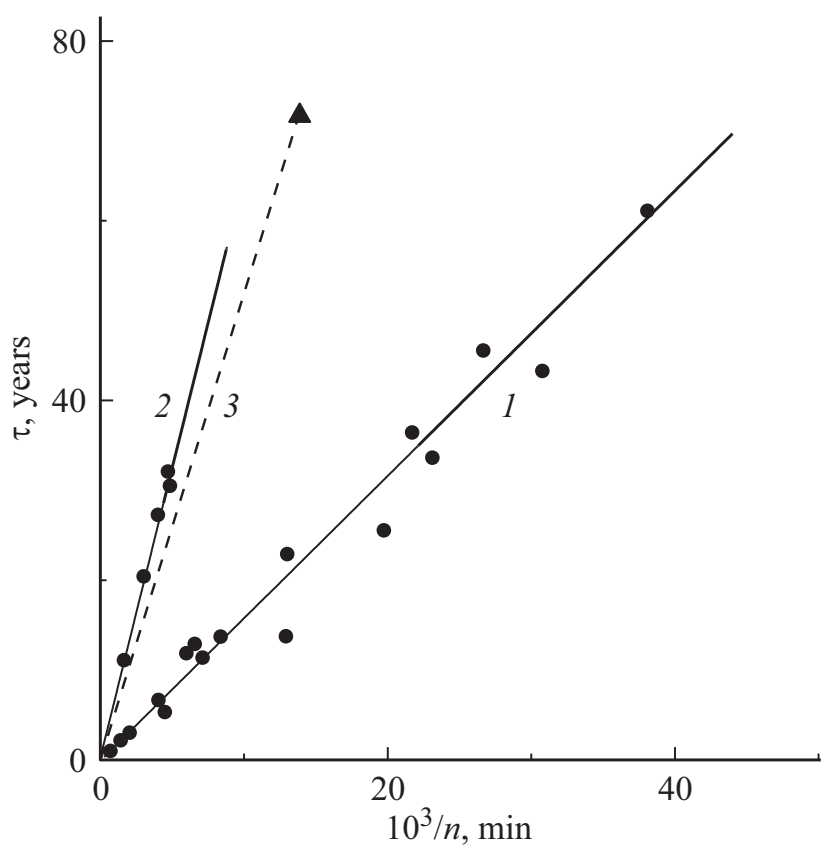

Рис. 1. Зависимость продолжительности жизни от величины пульса для млекопитающих (1), воробьиных птиц (2) и человека (3).

ция в состоянии мышечного покоя). Между указанными параметрами установлены определенные соотношения. Скорость основного обмена для всех животных (кроме прокариот) при одинаковой для всех теплокровных температуре тела $T$, приведенной к $39^{\circ} \mathrm{C}$, пропорциональна массе в степени 3/4 (закон Клайбера) [3]:

$$
Q=\beta \cdot m^{3 / 4},
$$

где $\beta$ - коэффициент, показывающий уровень окислительных процессов в организме. Удельная интенсивность обмена

$$
q=\frac{Q}{m}=\frac{\beta}{m^{0.25}}
$$

возрастает с уменьшением массы животного, что соответствует увеличению теплоотдачи в окружающее пространство.

Также установлено [4], что теплопродукция, произведенная за время одного цикла сердечного сокращения $t=\frac{1}{n},(n-$ частота сердечных сокращений $)$, одинакова для млекопитающих и птиц при достижении взрослого состояния

$$
a=\frac{Q}{n m}=(3 \pm 0.5) 10^{-4} \mathrm{kkal} / \mathrm{kg}
$$

Показано, что имеется связь между частотой сердечных сокращений и средней продолжительностью жизни животных $\tau$ (рис. 1) [5]:

$$
\tau=N n^{-1}
$$

где $N=0.8 \cdot 10^{9}$ для млекопитающих, 2.6 $10^{9}$ - для человека и $2.9 \cdot 10^{9}$ для воробьиных птиц $(N-$ число сердечных сокращений за время жизни).
Сравнение полученных значений $(N)$ с величиной константы Рубнера (Ru) (рис. 2) показывает линейную зависимость между этими величинами

$$
\mathrm{Ru}=\alpha^{*} N .
$$

Наклон прямой $\alpha^{*}=3.1 \cdot 10^{-4} \mathrm{kkal} / \mathrm{kg}$ практически совпадает со значением $a$ в формуле (3). Такое совпадение не является случайным, поскольку обе величины характеризуют уровень основного обмена за время одного сердечного сокращения. Из выражений (3)-(5) следует, что при постоянной температуре продолжительность жизни теплокровных животных определяется константой Рубнера, их массой и скоростью метаболизма

$$
\tau=\mathrm{Ru} \cdot m / Q \text {. }
$$

Отметим, что причина разной продолжительности жизни человека и других млекопитающих до сих пор остается невыясненной. Полагают, например, что это обусловлено разной величиной головного мозга. Влияние массы мозга $(B r)$ на продолжительность жизни часто описывают эмпирическим уравнением

$$
\tau \sim B r^{0.6} \mathrm{Ru} \cdot m^{-0.23} .
$$

Однако выражения (6) и (7) практически совпадают, поскольку масса мозга млекопитающих пропорциональна массе их тела $\left.B r \sim m^{0.75}\right)$. Следовательно, размер мозга не является независимым параметром, определяющим продолжительность жизни млекопитающих.

Из (6) следует, что увеличение продолжительности жизни при постоянных величинах $\mathrm{Ru}$ и $m$ может быть достигнуто за счет уменьшения скорости метаболизма $Q$. Рост $\tau$ наблюдается, например, для крыс и мышей в случае ограниченного, но сбалансированного питания, либо у гнобистов (безмикробных животных) [6]. В обоих случаях при уменышении $Q$ на 25-30\% наблюдается устойчивый рост продолжительности жизни до 1.5 раз.

Для оценки жизнедеятельности организмов используют также коэффициент Вант-Гоффа $Q_{10}$, который характеризует изменение скорости биохимических реакций при изменении температуры тела на $10^{\circ}$ [7].

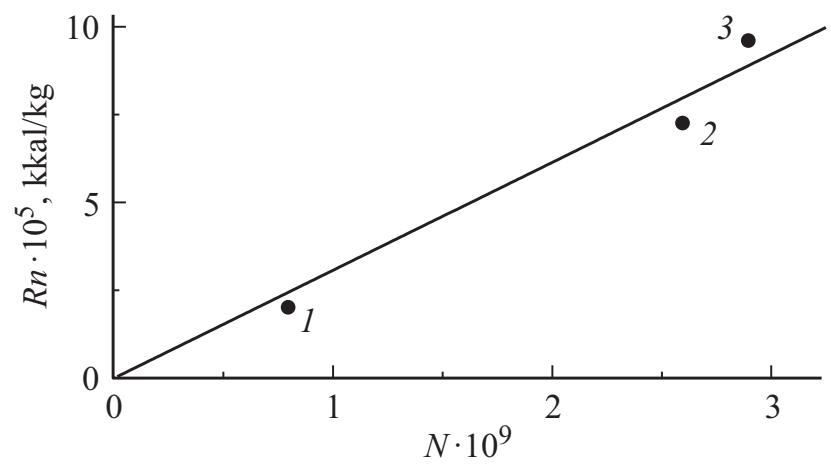

Рис. 2. Соотношение константы Рубнера $(\mathrm{Ru})$ и числа сердечных сокращений за время жизни $(N)$ для млекопитающих (1), человека (2) и воробьиных птиц (3). 


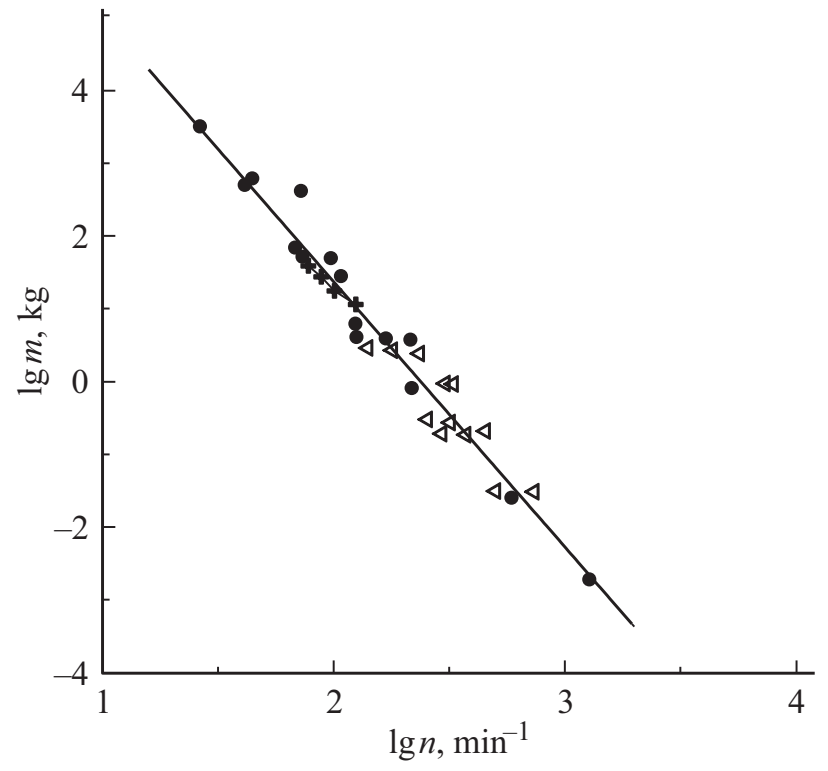

Рис. 3. Связь между массой тела и величиной пульса для млекопитающих $(\bullet)$, птиц $(\Delta)$ и человека во время роста $(+)$.

В пределах от 20 до $40^{\circ} \mathrm{C}$ величина коэффициента $Q_{10}$ изменяется в $2-3$ раза. Также в литературе приводятся данные по влиянию температуры тела на частоту сердечных сокращений и продолжительность жизни животных (в основном насекомых [8]). Следует, однако, отметить, что анализ данных подобного рода носит не количественный, а качественный, иллюстративный характер. Для гомойотермных животных влияние температуры тела на продолжительность их жизни не рассматривалось. Полагают, например, что влияние температуры на биологические реакции является незначительным по сравнению с физическим действием температуры на метаболизм организмов [9]. Также отмечается, что поскольку скорость обменных процессов в живых организмах катализируется ферментами, то при изменении температуры скорость биохимических реакций может дополнительно измениться за счет зависящей от температуры энзиматической активности [10].

В настоящей работе в рамках энергетических представлений рассматривается влияние температуры в совокупности с другими параметрами, определяющими жизнедеятельность, на продолжительность жизни теплокровных животных. Важность температуры для проблемы старения очевидна и вытекает, по крайней мере, из двух соображений. Во-первых, в живом организме протекает множество биохимических реакций, скорость которых экспоненциально зависит от температуры. Во-вторых, известно, что при одинаковых весовых параметрах хладнокровные животные живут дольше теплокровных.

Поскольку точность оценки частоты сердечных сокращений $n$ существенно выше точности определения величины $\tau$, то для выявления зависимости $\tau$ от различных параметров использовали величину $n$.
На рис. 3 приведена связь между массой животных и величиной пульса $n[8,11,12]$ Эта зависимость может быть представлена в виде:

$$
n=\frac{A_{1}}{m^{0.27}}
$$

где $A_{1}-$ постоянная. Указанная зависимость выполняется также и в процессе роста одного индивидуального организма.

Рассмотрим зависимость величины $n$ от температуры тела. На рис. 4 для разных животных приведена зависимость $n$ от $T$ в аррениусовских координатах [8]. Видно, что наклон прямых практически одинаков (в том числе и для холоднокровной черепахи), что свидетельствует о постоянстве энергии активации. На рис. 5 показана зависимость произведения частоты пульса на приведенную массу $n m^{0.27}$ от обратной температуры. Эта зависимость может быть представлена в виде:

$$
n=\left(\frac{A_{2}}{m^{0.27}}\right) \exp (-E / k T),
$$

где $A_{2}-$ постоянная, $k-$ постоянная Больцмана, энергия активации $E=(21 \pm 1) \mathrm{kkal} / \mathrm{mol}$. Полученное значение энергии активации практически совпадает с энергией активации $E=21.2 \mathrm{kkal} / \mathrm{mol}$, определенной при лабораторном исследовании ферментативного катализа аденозинтрифосфорной кислоты (АТФ) $[13,14]$. В качестве катализатора реакции гидролиза АТФ использовали либо обычный кислотный катализатор (гидроксоний

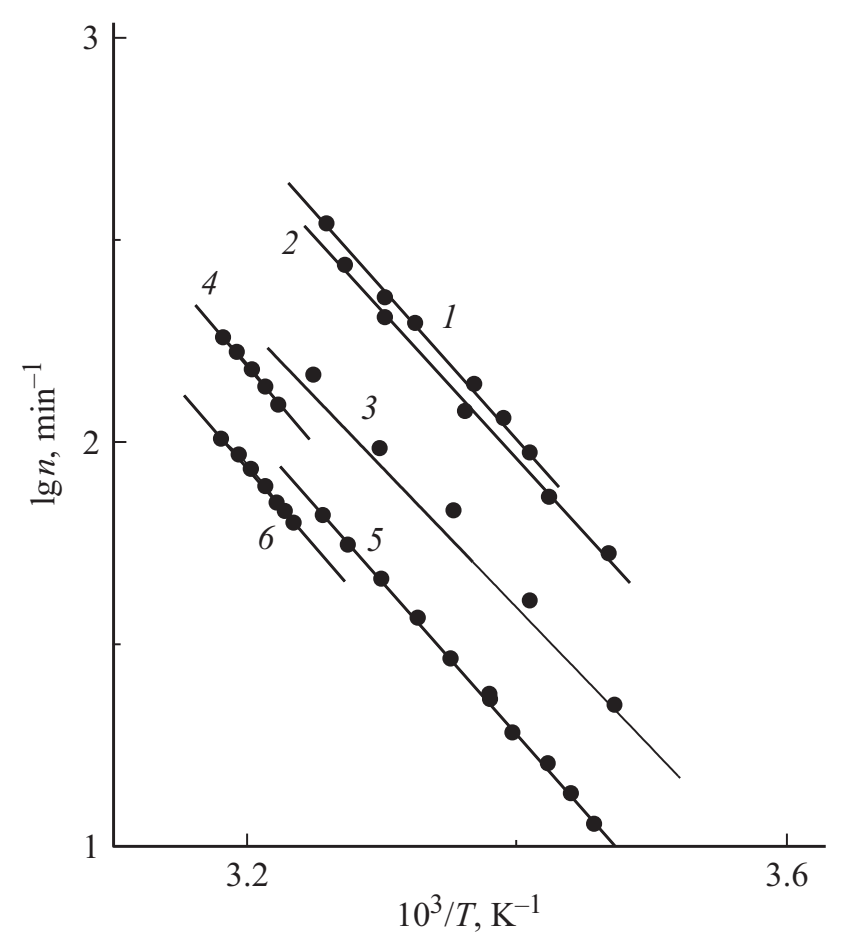

Рис. 4. Зависимость частоты сердечных сокращений от температуры тела для различных животных: 1 - колибри, $2-$ мышь, 3 - хомяк, 4 - ребенок, 5 - черепаха, 6 - взрослый человек. 


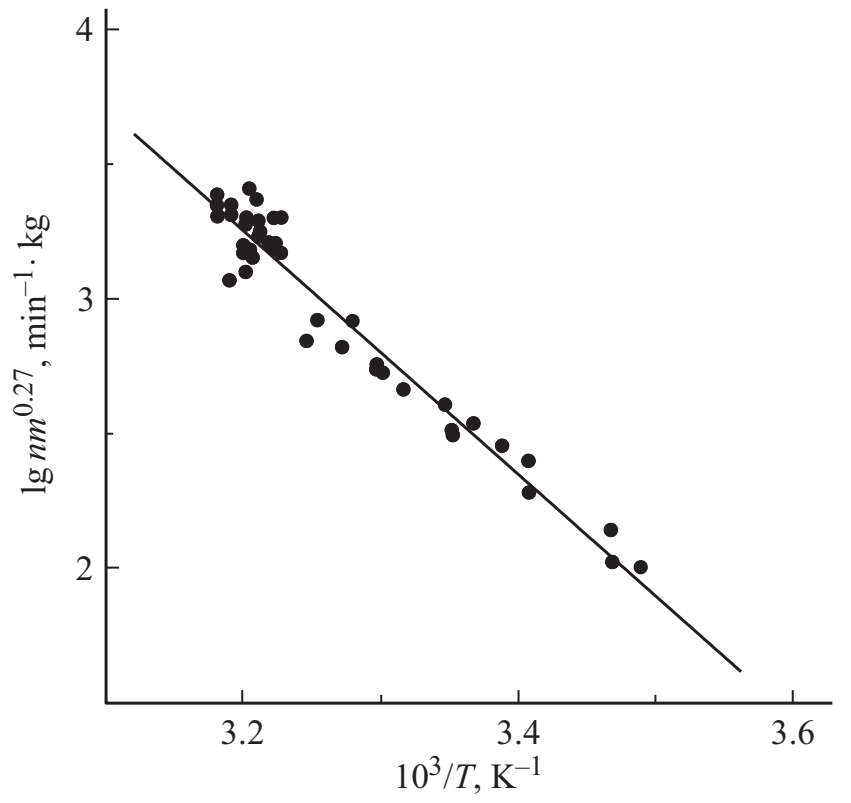

Рис. 5. Зависимость частоты сердечных сокращений, приведенной на массу от обратной температуры для гомойотермных животных.

$\mathrm{H}_{3} \mathrm{O}^{+}$), либо ферментативный катализатор - миозин. Каталитический эффект происходит при образовании комплекса АТФ-фермент. При этом скорость реакции линейно возрастает с увеличением концентрации субстрата. Таким образом, увеличение скорости ферментативного разрыва макроэргических связей в молекулах АТФ осуществляется как за счет уменьшения энергетического барьера разрыва $\mathrm{P}-\mathrm{O}-$-вязей, так и за счет линейного возрастания с ростом концентрации АТФ предэкспоненциального множителя. (Отметим, что скорость неферментативного гидролиза АТФ в нормальных условиях мала, поскольку энергия $\mathrm{P}-\mathrm{O}-$-вязи составляет около $86 \mathrm{kkal} / \mathrm{mol}[15])$.

Оценим влияние температуры на величину основного обмена. Используя выражения (3) и (9) коэффициент $\beta$, входящий в уравнение Клайбера (1), может быть записан в виде

$$
\beta=A_{2} a \exp \left(-\frac{E}{k T}\right) .
$$

Следовательно, уравнение основного обмена, показывающее соотношение между массой животного и скоростью метаболизма, будет содержать фактор Больцмана

$$
Q=\left(A_{2} a \exp \left(-\frac{E}{k T}\right)\right) m^{3 / 4} .
$$

Для холоднокровных насекомых и рыб в литературе рассматривается влияние температуры тела на величину основного обмена [16]. На рис. 6 приведена зависимость стандартного обмена у нерки от температуры [17]. Видно, что в координатах $\lg Q-1 / T$ наблюдается два участка с разными наклонами. Это свидетельствует о том, что в отличие от теплокровных животных активность ферментов для хладнокровных организмов может зависеть от температуры, что существенным образом сказывается на величине энергии активации (Для нерки при высоких температурах $E=18.4 \mathrm{kkal} / \mathrm{mol}$ и $E=7.9 \mathrm{kkal} / \mathrm{mol}$ при низких температурах).

Оценим изменение величины $Q$ для теплокровных животных. Известно, что в летнее время температура тела сурка составляет $37-38^{\circ} \mathrm{C}$, а зимой в гомойотермном состоянии спячки она падает до $(4 \pm 3)^{\circ} \mathrm{C}[7,18]$. При этом потребление кислорода уменьшается в 41 раз. Согласно (11), изменение скорости потребления кислорода можно оценить как

$$
\Delta \lg Q=\frac{E \cdot \Delta(1 / T)}{2.3 k} .
$$

При $\quad E \approx 20 \mathrm{kkal} / \mathrm{mol} \quad$ и $\quad \Delta(1 / T) \approx 0.38 \cdot 10^{-3}{ }^{\circ} \mathrm{C}^{-1}$ $\Delta \lg Q=1.65$. Это означает, что в спячке сурок должен потреблять кислорода в 45 раз меньше, чем в активном состоянии летом.

Из выражений (6) и (11) следует, что продолжительность жизни гомойотермных животных может быть записана в виде

$$
\tau=\left(\frac{\mathrm{Ru} \cdot m^{0.25}}{A_{2} a}\right) \exp (E / k T) .
$$

Таким образом, видовая продолжительность жизни теплокровных животных является функцией константы Рубнера, величины основного обмена, массы и температуры тела. Снижение температуры тела должно приводить к снижению уровня метаболизма и росту продолжительности жизни. Особенно заметен рост $\tau$ у

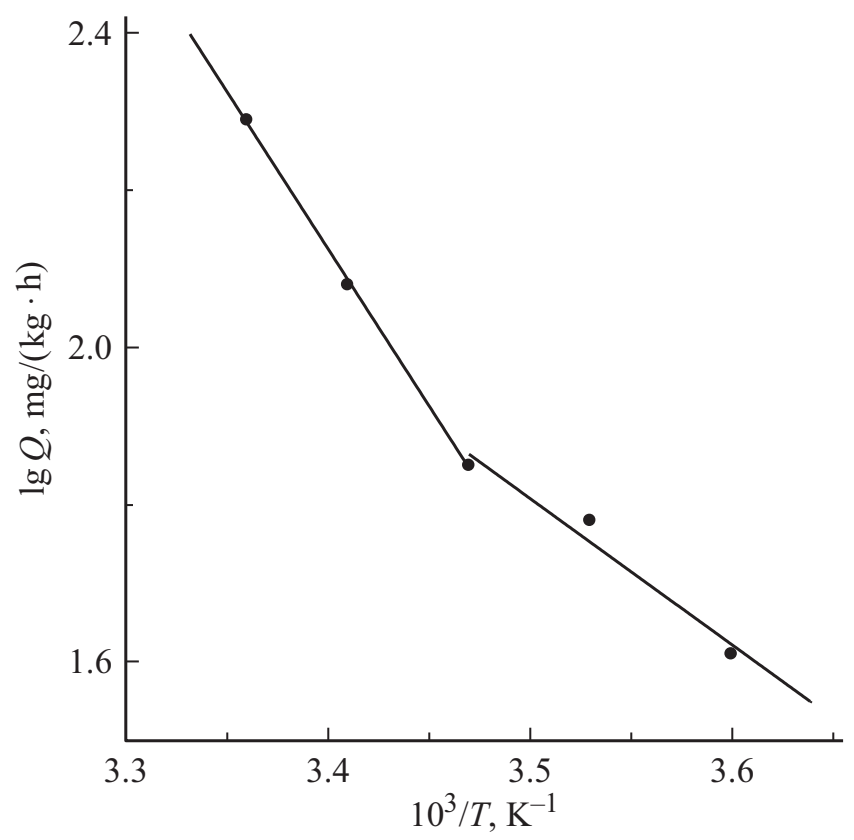

Рис. 6. Зависимость стандартного обмена (потребление кислорода) у нерки от температуры. 
видов млекопитающих, впадающих в сезонную спячку или в состояние ежедневного оцепенения. Так если продолжительность жизни обычной мыши составляет 3-4 года, то виды этого же семейства, впадающие в спячку, доживают до 8 лет [18]. Отметим, что при снижении температуры тела на один градус продолжительность жизни человека может возрасти на $11 \%$, и при средней продолжительности жизни $\tau=80$ лет она возрастет до 88 лет.

Из уравнения (11) следует, что для птиц, температура тела которых выше температуры тела млекопитающих, составляющих соответственно 43 и $38^{\circ} \mathrm{C}$, при одинаковой массе тела уровень базального метаболизма в 1.7 раза выше. Однако, как следует из данных рис. 1, продолжительность жизни птиц заметно больше, чем у млекопитающих.

В литературе предлагаются различные гипотезы для объяснения долгоживучести птиц: регенерация нервной ткани и нейронов головного мозга до конца жизни птиц [19]; более низкий темп накопления повреждений ДНК [20]; эффективная резистентность клеток к оксигенным повреждениям [21]. Вероятно, имеются и другие факторы, которые могут объяснить увеличение продолжительности жизни птиц. Так, например, если исходить из гипотезы Аршавского о положительном влиянии двигательной активности на величину $\tau$ [22], можно предположить, что этот фактор может иметь заметное влияние, поскольку энергетические расходы птиц во время полета, который является основным способом их перемещения, значительно превосходят расходы энергии млекопитающих во время их передвижения. Увеличение физических нагрузок на организм, как известно, ведет к улучшению работы всех систем и органов, что делает организм птиц более приспособленным к различным неблагоприятным воздействиям и замедляет процесс старения.

Итак, проведенные в рамках энергетической концепции оценки влияния температуры на параметры, определяющие жизнедеятельность организмов, позволяют сделать следующие выводы:

- впервые получено выражение для зависимости продолжительности жизни теплокровных животных (человека, млекопитающих и воробьиных птиц) от их массы, константы Рубнера, величины основного обмена и температуры тела, что существенно расширило возможности энергетической теории для анализа и осмысления биохимических процессов в живых организмах.

- показано, что величина энергии активации, входящая в фактор Больцмана для величины основного обмена и продолжительности жизни, близка к энергии ферментативного гидролиза макроэргических связей в аденозинтрифосфорной кислоте.

- показано, что полученное уравнение основного обмена, содержащее больцмановский фактор, позволяет прогнозировать изменение скорости метаболизма для животных в гомойотермном состоянии в достаточно широком интервале температур.

\section{Список литературы}

[1] Алимов А.Ф., Казанцева Т.И. // Журнал общей биологии. 2008. T. 69. № 5. C. 355-363.

[2] Finch C.E. Longevity. Senescence, and the Genome. Chicago, London: The University of Chicago Press, 1990.

[3] Kleiber M. // Phys. Rev. 1947. Vol. 27. N 3. P. 511-541.

[4] Brody S. Bioenergetics and growth. NY: Reinhold, 1945. $1023 \mathrm{p}$.

[5] Аршавский И.А. // Успехи современной биологии. 1977. T. 87. C. $287-304$.

[6] Подопригора Г.И. // Природа. 1978. № 6. С. 3-15.

[7] Ленинджер А.Л. Основы биохимии: Нельсон Д., Кокс М. Биоэнергетика и метаболизм. М. 1985. Т. 2. С. 501-546.

[8] Сравнительная физиология животных / Под ред. Л. Проссера. 1978. М.: Мир. Т. 3. 653 с.

[9] Зотин А.И., Зотин А.А. Направление, скорость и механизмы прогрессивной эволюции. М.: Наука, 1999.

[10] Легуше Э.Ф. Лекции по экологии. Уфа: УГАТУ, 2010. 148 с.

[11] Млекопитающие Советского Союза / Под. ред. В.Г. Гентлера, М.П. Наумова. М.: Высшая школа, 1967. 1014 с.

[12] Жизнь животных / Под ред. Л.П. Зенкевич. М.: Просвещение, 1971. Т. 6. 694 с.

[13] Березов Т.Г., Коровкин Б.Ф. Биологическая химия. М.: Медицина, 1998. $704 \mathrm{c}$.

[14] АФанасьев В.А., Заиков Г.Е. В мире катализа. М.: Наука, 1977. $107 \mathrm{c}$.

[15] Веденеев В.И., Гуревич Л.В. и др. Энергия разрыва химических связей. М.: Наука, 1977. 102 с.

[16] Ивлева И.В. // Успехи современной биологии. 1972. Т. 73. № 1. С. 134-155.

[17] Слоним А.Д. Экологическая физиология животных. М.: Высшая школа, 1971. 448 с.

[18] Калабухов Н.И. Спячка млекопитающих. М.: Наука, 1985. $260 \mathrm{c}$.

[19] Weissman T., Noctor S.C., Clinton B.K., Honig L.S., Kriegstein A.R. // Cereb. Cortex. 2003. Vol. 13. N 6.

[20] Barja $G$. Mitochondrial free radical production and aging in mammals and birds. 1998. Ann NY: Acad. Sci., 854 p.

[21] Ogburn C.E., Carlberg K., Ottinger M.A., Holmes D.J., Martin G.M., Austad S.N. // J. Gerontol. A Biol. Sci. Med. Sci. 2001. 56.

[22] Аршавский И.А. Физиологические механизмы и закономерности индивидуального развития. 1982. М.: Наука, $270 \mathrm{c}$. 